\title{
PERFIL PROFISSIOGRÁFICO DOS EGRESSOS DO PROGRAMA DE MESTRADO PROFISSIONAL EM ADMINISTRAÇÃO DE UMA INSTITUIÇÃO DE ENSINO DO INTERIOR DO ESTADO DE SÃO PAULO
}

\author{
Professiographic Profile of Graduates from a Professional \\ Master Program in Administration of an Educational Institution \\ from São Paulo State Contryside
}

Recebido em 15.12.09 / Aceito em 30.05.10

Antonio Carlos Giuliani ${ }^{1}$

\section{Resumo}

Este artigo apresenta os resultados de uma pesquisa realizada junto a 32 egressos de um programa de mestrado profissional em Administração de uma instituição de ensino do Interior do Estado de São Paulo. O objetivo foi o de confrontar as autopercepções e as expectativas dos ex-alunos em relação ao curso, com as propostas da coordenação do programa e as normas da CAPES para cursos de mestrado profissional. Os resultados do estudo sugerem que o programa é bem-sucedido em selecionar profissionais com variada experiência profissional; no entanto, de maneira contrária ao esperado, a maioria dos alunos do mestrado profissional considera as atividades acadêmicas de magistério e pesquisa como principais, relegando a um segundo plano a qualificação de alto nível para atuar no mercado empresarial. Espera-se, por meio do presente estudo, incentivar o debate acerca da adequação curricular e estrutural dos cursos para o cumprimento de seus propósitos.

Palavras-chave: Perfil Profissiográfico; Mestrado Profissional; Adequação Curricular.

\section{Abstract}

This article presents the results of a survey carried through with 32 graduates from a professional master's degree program in administration of an educational institution from São Paulo state countryside. The objective was to compare the ex-students self-perceptions and expectations about the course, both with the

\footnotetext{
1 Coordenador do Mestrado Profissional em Administração da Faculdade de Gestão e Negócios, Universidade
} Metodista de Piracicaba, Área de Marketing. E-mail: cgiuliani@unimep.br. 
program coordination proposals and CAPES regulation for professional master's courses. The results suggest that the program is successful in selecting professionals with varied experience, however, in opposite of the expected result, most of the professional masters students consider the academic activities of teaching and research as the principal, leaving in the second plan a high-level qualification to act on the business market. We hope through this study, to encourage debate about the courses structural and curricular adequacy to accomplish its purposes.

Keywords: Professiographic Profile; Professional Master; Curriculum Adequation.

\section{Introdução}

As instituições de ensino superior no Brasil, notadamente as particulares, têm desenvolvido atividades para suprir demandas dos setores não-acadêmicos da economia. O estabelecimento de parcerias entre universidades e empresas visa, a princípio, o desenvolvimento da ciência e tecnologia como base para o crescimento contínuo e de qualidade em áreas estratégicas, além da formação de pessoal capacitado para exercer ações técnicas e de investigação.

Para atender a essas demandas e com base nas Portarias no. 47, de 17/10/1995, e no‥ 80, de 16/12/1998, da Coordenação de Aperfeiçoamento de Pessoal de Nível Superior (CAPES), que determinam a criação e normalização referentes aos cursos de mestrado orientados para a formação profissional, o mestrado profissional vem sendo objeto de discussão na comunidade acadêmica, no que se refere aos problemas vinculados à articulação entre as várias formas de pós-graduação, as expectativas profissionais e as necessidades de mercado.

A ênfase sobre o ensino em nível de pós-graduação e, concomitantemente, sobre o desenvolvimento científico-tecnológico do país, justifica-se pela necessidade de responder às demandas econômicas, sociais, políticas e psicológicas necessárias à formação de recursos humanos de alta qualificação, tanto para o campo da pesquisa, quanto para o magistério superior.

O papel do mestrado profissional no Brasil, por sua vez, é definido com base em três constatações, segundo Ribeiro (2005): (i) a sociedade atual requer uma formação cada vez mais qualificada; (ii) constata-se que boa parte dos mestres e uma parte significativa dos doutores não atuam no ensino superior; e (iii) não há preconceito da CAPES em relação à transferência de conhecimento científico para as empresas ou para o mercado, desde que a sociedade, como um todo, o setor público e os movimentos sociais, em particular, também sejam alvo dessa transferência.

A essas considerações, acrescem-se alguns pontos mais específicos:

a) a sociedade atual requer formação cada vez mais qualificada, mesmo para setores que não lidam com a docência nem com a pesquisa de ponta; assim, a pós-graduação pode contribuir para a formação desses profissionais. Mesmo que se continue formando prioritariamente docentes para o ensino superior, estudo realizado por Veloso (2005) já apontava que, na década de 1990, parte substancial dos egressos da pós-graduação destinavam-se ao mercado profissional, em detrimento da docência;

b) a expansão quantitativa de cursos de pós-graduação está ocorrendo de forma acelerada no Brasil, incluindo-se cursos de aperfeiçoamento, especialização, mestrado e doutorado;

c) é de fundamental interesse para a universidade, para o curso e para comunidade conhecerem em detalhes o perfil dos seus egressos. 


\section{Obbjetivo e Relevância do Estudo}

O objetivo do presente estudo é analisar os egressos do programa de mestrado profissional em Administração (MPA) de uma instituição de ensino superior do interior do estado de São Paulo, e confrontar suas autopercepções e expectativas em relação ao curso com as propostas da coordenação do programa e da CAPES para cursos de mestrado profissional.

Vários autores analisam os mestrados profissionais e a adequação das mudanças no mundo dos negócios, ambiente institucional e currículo do curso (CASTRO, 2005; IKEDA; CAMPOMAR; OLIVEIRA, 2005; FISCHER, 2003; GOUVÊA; ZWICKER, 2000; BOJE, 1996). Esses autores apontam para a importância e atualidade do tema abordado como norteador para a gestão dos mestrados profissionais. Tais cursos são espaços privilegiados para o exercício de diálogo inter e multidisciplinar, promovendo a formação profissional, devendo a pesquisa constituir-se como atividade reflexiva aos campos profissionais.

Devido ao caráter de qualificação profissional de alto nível proposto pelos mestrados profissionais, destaca-se o seguinte pressuposto, que será testado neste estudo: A maioria dos alunos do MPA considera as atividades acadêmicas de magistério e pesquisa como complementares, preferindo como ocupação principal a qualificação de alto nível para atuar no mercado empresarial.

\section{Revisão do Conhecimento}

\subsection{A pós-graduação no Brasil}

O ensino de pós-graduação no Brasil desenvolveu-se a partir da década de 1960, quando os cursos de pós-graduação foram oficialmente previstos na Lei no. 4024, de 20 de dezembro de 1961 (Lei de Diretrizes e Bases da Educação Nacional).

Seu desenvolvimento aconteceu em um período de rápido crescimento das matrículas no ensino superior. Segundo Cunha (1974a), um dos fatores de estímulo aos cursos de pósgraduação foi a necessidade de formação de recursos humanos. O desenvolvimento do ensino de pós-graduação no Brasil evitaria a queda da qualidade na graduação. Nesse contexto, o Ministério da Educação e Cultura encaminhou o pedido de regulamentação dos cursos de pósgraduação ao Conselho Federal de Educação em 1965. Segundo Cunha (1974b), o pedido apontava três motivos que exigiam a instauração dos cursos de pós-graduação:

a) formar professores competentes, atendendo à expansão quantitativa do ensino superior e assegurando qualidade;

b) estimular o desenvolvimento da pesquisa científica;

c) assegurar a capacitação de recursos humanos do mais alto nível para fazer face às necessidades do desenvolvimento em todos os setores.

Foi por meio do Parecer 977/65, emitido pelo Conselheiro Professor Newton Sucupira, que se estabeleceu a distinção entre pós-graduação stricto sensu e lato sensu. O parecer é concluído com a afirmação de que a pós-graduação brasileira deveria limitar-se aos cursos stricto sensu, que se referem à abordagem acadêmica (mestrados e doutorados). Os lato sensu, por sua vez, relacionam-se aos cursos voltados para a demanda do mercado como, por exemplo, o MBA - master in business administration. 
Para Motta (1997) e Fischer (2002), as décadas de 1960 e 1970 foram os tempos dos investimentos na formação de pessoal, especialmente no exterior, e do apoio à implantação dos cursos de mestrado e início dos doutorados. No período anterior (década de 1950), a CAPES fomentou a formação de mestres e doutores, os quais foram responsáveis, nas décadas de 1960 a 1980, pela implantação dos cursos de pós-graduação.

Foi em 1972 que o Ministério da Educação (MEC) regulamentou os cursos de pósgraduação para todas as áreas do conhecimento, chamando-os de mestrado e de doutorado. Em 30 de julho de 1975, foi aprovado, pelo Presidente da República, o Plano Nacional de PósGraduação (PNPG), com vigência por cinco anos a partir de sua aprovação e propondo as medidas iniciais para a definição da política de pós-graduação. Definiu-se, como diretriz fundamental, que os cursos de pós-graduação stricto sensu se desenvolvessem e se consolidassem como agentes de formação de pessoal para o setor gerador de recursos humanos para a sociedade, as universidades (LHULLIER, 1978). Ressaltou-se a importância da transformação dos cursos de mestrado e de doutorado em núcleos formadores de pessoal qualificado para o magistério superior e a pesquisa.

\subsection{O mestrado profissional}

Na década de 1990, os programas de MBA ganharam sólida reputação e expandiram-se para além das fronteiras norte-americanas, ganhando força no Brasil, com o crescimento do ensino profissionalizante de gestão.

A educação executiva e os MBAs têm sido objeto de intensa atenção de pesquisadores (ver, por exemplo, GIOIA; CORLEY, 2002; MINTZBERG; GOSLING, 2002; MINTZBERG; LAMPEL, 2001; WARDE, 2000; FOX; GREY, 2000; ANTONACOPOULOU, 1999; DEHLER; WELSH; LEWIS, 1999; GOLD; HOLMAN; THORPE, 1999; GREY; KNIGHTS; WILLMOTT, 1996; WILLMOTT, 1994; WARNER, 1990).

Ao analisar estudos sobre o mestrado profissional, podem ser encontrados vários que merecem destaque, como o de Ruas (2003), que trata da questão da identidade dos programas de mestrado profissional em administração, reconhecendo sua importância como supridores de demandas dos executivos de empresas e propondo um aprofundamento do debate acerca do desenvolvimento de competências. Fischer (2003) reflete sobre o mestrado profissional como modalidade inovadora e arriscada, afirmando que tensões e dilemas têm marcado a trajetória desse modelo de ensino. A autora afirma, ainda, que o mestrado profissional não é um curso excludente, sendo ambicioso ao tentar conciliar os paradoxos dos eixos acadêmico e profissional.

Embora o mestrado profissional seja fenômeno relativamente recente na pós-graduação brasileira, enquanto prática acadêmica institucionalizada (já que os primeiros cursos datam de meados dos anos 1990), é reconhecido como necessidade e rota alternativa de formação e uma tentativa de orientar o ensino para a aplicação.

O conceito de mestrado profissional, no entanto, não é novo; a ideia de cursos orientados para a capacitação profissional está expressa no Parecer no. 977/65, do Conselho Federal de Educação, que já propunha a criação de cursos de pós-graduação orientados para a formação profissional. O mestrado profissional foi regulamentado em 1995, seguindo-se portarias e resoluções que tentam estabelecer as diferenças entre cursos acadêmicos e profissionais. O mestrado profissional é um mestrado stricto sensu e, portanto, obedece aos procedimentos típicos dessa modalidade. Para Quelhas, Faria Filho e França (2005), o curso procura formar um profissional 
capacitado para pesquisa, desenvolvimento e inovação e que seja, também, capaz de atuar como multiplicador, repassando seus conhecimentos para os demais profissionais de seu campo de atuação.

Segundo definição da CAPES sobre essa modalidade de curso:

\begin{abstract}
Mestrado profissional é a designação do mestrado que enfatiza estudos e técnicas diretamente voltadas ao desempenho de um alto nível de qualificação profissional. Esta ênfase é a única diferença em relação ao acadêmico. Confere, pois, idênticos grau e prerrogativas, inclusive para o exercício da docência e, como todo programa de pós-graduação stricto sensu, têm a validade nacional do diploma condicionada ao reconhecimento prévio do curso (PARECER CNE/CES 0079/ 2002).
\end{abstract}

Para Ribeiro (2005), a principal diferença entre o mestrado acadêmico e o mestrado profissional é o resultado almejado. No mestrado acadêmico, pretende-se, pela imersão na pesquisa, formar, em longo prazo, um pesquisador. No mestrado profissional, deve ocorrer a imersão na pesquisa, mas o objetivo principal é formar alguém que, no mundo profissional, saiba localizar, reconhecer e identificar a pesquisa de modo a agregar valor às suas atividades.

O mestrado profissional pode variar quanto aos públicos aos quais se destina, quanto à estrutura, ao local, ao tempo de duração, às exigências de dedicação do estudante e à natureza do ensino. Fischer (2003) apresenta dois modelos: o curso generalista e o curso focalizado. O generalista é típico da área de Administração, enquanto o focalizado é identificável em áreas tecnológicas e de políticas públicas. A autora descreve os dois modelos como segue:

a) o mestrado profissional generalista prepara profissionais multiqualificados em nível estratégico; atrai alunos com experiência anterior, critério valorizado na seleção;

b) o mestrado profissional focalizado prepara profissionais para setores específicos de atividades, possibilitando especializações e maior instrumentalidade para lidar com problemas concretos.

Ambos podem ser oferecidos a públicos iniciantes ou já experientes, permitindo maior desenvolvimento profissional. Ao concluí-los, o aluno recebe o título de mestre, podendo também, com essa credencial, ensinar. O trabalho de conclusão do mestrado profissional configurase como dissertação que demonstre domínio do objeto de estudo, além da investigação aplicada à solução de problemas. Deve-se descrever e discutir os resultados, conclusões e recomendação de aplicações práticas, pautadas sobre referenciais teóricos. O conteúdo dos trabalhos pode ser organizado como estudos de casos, desenvolvimento e descrição de metodologias, tecnologias e softwares, ou patentes que decorram de pesquisas aplicadas.

Segundo Castro (2005), o mestrado profissional é um mestrado para quem trabalha; assim, o horário de oferecimento de disciplinas deve ser adequado ao perfil do aluno, que teria noites, finais de semana e férias para estudar.

\title{
2.3 O discurso da crítica aos mestrados profissionais
}

Embora previsto na regulamentação inicial da pós-graduação brasileira, o mestrado profissional é um formato mais recente de curso de pós-graduação e, assim, é alvo de polêmica na comunidade científica, rejeitado por áreas tradicionais e confundido pela sociedade com os MBAs.

Estudos realizados mostram que os mestrados profissionais estão ganhando legitimidade e as barreiras mais sérias parecem estar sendo superadas. 
Castro (2005) afirma que a ideia do mestrado profissional é freada em função do mestrado acadêmico, que lhe tira a vida própria. O autor diz que, para que esses mestrados tenham vida própria, a sua supervisão pela CAPES deve ser independente do que prevalece para as áreas acadêmicas. Fischer (2005) mostra que a hipervalorização do mestrado acadêmico durante muito tempo é reforçada pelo esforço que as áreas aplicadas fazem no sentido de se constituírem e serem valorizadas como produtoras de pesquisa e conhecimento, já que as áreas jovens no contexto da pós-graduação parecem ter criado rejeição ao formato diferenciado do mestrado profissional.

Para Fischer (2005), os cursos de mestrado profissional podem ser estruturados por princípios de flexibilidade, organicidade, inovação e aplicabilidade. Piquet e Leal (2005), por sua vez, afirmam que os mestrados profissionais são experiências de inovação e reinvenção das práticas acadêmicas, necessitando também de padrões de exigência tão rigorosos quanto os mestrados acadêmicos, mas com critérios diferentes.

O grau de mestre é, há tempos, o título mais presente no cenário acadêmico brasileiro. Ao trazer o mestrado profissional para o cenário de títulos acadêmicos, os autores deixam evidente a falta de discussão substantiva, não apenas sobre o mestrado profissional, mas sobre o mestrado em si.

Um ponto de inquietação por parte da comunidade acadêmica sobre o papel do mestrado profissional é abordado no documento anexo à ata da $65^{\underline{a}}$ reunião do Conselho Técnico Científico da CAPES (2002) e ressalta que os títulos referentes aos cursos profissionais devem ser aceitos para o ingresso e ascensão na carreira docente, notadamente do ensino superior, e, neste caso, serem considerados para o cumprimento das exigências da LDB sobre qualificação docente. É importante considerar que não compete à CAPES se posicionar sobre assuntos do âmbito da autonomia universitária, como títulos e que tipo de formação admitirão as universidades em seus concursos para a carreira docente. Algumas poderão aceitar o título do mestrado profissional, assim como outras poderão não aceitar ou aceitá-lo apenas para algumas áreas ou disciplinas.

O mestrado profissional vem surgindo em áreas das mais diferentes naturezas. Áreas como as de Direito, Educação e Ciências Agrárias, segundo Barros, Valentim e Melo (2005), opõem-se à instalação dessa modalidade de mestrado.

Outro ponto de rejeição aos mestrados profissionais é abordado por Mattos (1997), e está relacionado à questão do acesso a recursos e a títulos, característica da formação social brasileira. Para o autor, a rejeição é gerada, principalmente, pelo receio de que o crescimento dessa nova modalidade de pós-graduação Stricto sensu venha a prejudicar o desenvolvimento da formação acadêmica tradicional (mestrado acadêmico e doutorado).

Os mestrados profissionais são confundidos com os MBAs, embora o mestrado profissional tenha se tornado uma realidade. Apesar de ser mal compreendido e mal absorvido pela comunidade acadêmica, o curso está se desenhando, segundo Fischer (2003), como uma fusão entre os cursos acadêmicos e os MBAs. Ele é mais sedutor que os cursos de MBA, pois permite, ironicamente, ensinar e compreender que necessitamos do aprender a aprender.

O mestrado acadêmico busca expor o mestrando à literatura científica da área e treinálo em atividades de pesquisa, qualificando-o para o magistério superior. Já o mestrado profissional é uma oportunidade de maior aproximação entre os trabalhos conduzidos pela universidade e as demandas existentes no campo social e profissional.

É importante ressaltar, mais uma vez, que ambas as modalidades estão sujeitas à mesma legislação que rege a autorização de reconhecimento de cursos pela CAPES e devem apresentar padrões de qualidade equivalentes. Conforme Portaria da CAPES de № 80, de 16 de dezem- 
bro de 1998, o que deve ser perseguido é a garantia da qualidade e, nesse sentido, tanto os mestrados acadêmicos quanto os profissionais, embora cumprindo propostas diferenciadas de habilitação, devem assegurar formação de igual nível e qualidade. As universidades são fóruns privilegiados para proporcionar discussões entre aqueles que formam o complexo tecido social. Nesse sentido, Mattos (1997, p. 45) argumenta que:

[...] se a academia se supõe credenciada, pela natureza do que produz, a falar ao mundo da empresa, do planejamento e da produção, é forçoso que aceite discutir formas alternativas de produzir conhecimento crítico com finalidades práticas que não o atendimento de suas próprias preocupações e polêmicas internas, ou a manutenção de suas tradições e instituições.

A qualificação profissional daqueles que atuam em diferentes áreas de conhecimento é uma exigência tanto mercadológica, quanto social em sentido amplo. Um curso de formação stricto sensu pode ser visto como importante mecanismo de ajuste social entre instituições que há muito tempo deveriam estar dialogando em prol do desenvolvimento integrado de campos de conhecimento e campos de aplicação de diferentes setores da sociedade. Os mestrados profissionais, embora alvo de críticas, têm o compromisso de promover o encurtamento das distâncias que, historicamente, se criaram entre a academia e outros setores da sociedade. Seu papel é capacitar o mestrando para a problematização do seu cotidiano de trabalho em bases científicas.

É importante ressaltar que a ênfase para o mestrado acadêmico, com a exclusão da vertente profissional, pressupunha que a mesma seria suficiente para assegurar a formação de pessoal de alta qualificação para atuar nas áreas profissionais, nos institutos tecnológicos e nos laboratórios industriais. Hoje, entende-se que os mestrados profissionais têm a responsabilidade de unir o mundo da academia e o mundo do trabalho, reduzindo as tensões e dilemas e compreendendo que todos os modelos de ensino são perecíveis e reinventá-los é uma verdadeira missão de desconstrução e reconstrução.

Estudo realizado por Wood Jr. e Paula (2004) verifica os mestrados profissionais em Administração sob uma perspectiva crítica, analisando o perfil dos alunos e do corpo docente de seis instituições (FGV-EAESP, IBMEC-SP, FGV-EBAPE, PUC-RJ, UFBA e UFRGS). Ao apresentar a origem dos alunos, os autores destacam o fato de que os mestrados profissionais em Administração são cursos de tempo parcial e quase todos os estudantes os realizam à noite e nos finais de semana, sem se afastarem de seus empregos. A maioria desses estudantes vem de empresas médias e grandes, apresentam idades superiores a dos alunos dos MBAs internacionais e situam-se em postos relativamente mais altos na hierarquia das empresas. O percentual de mulheres é baixo, embora crescente. Os cursos são financiados (total ou parcialmente) pelas empresas nas quais os profissionais atuam. O corpo docente, composto por doutores em sua grande maioria, possui atividades fora da academia, seja como executivo em empresas públicas e privadas, seja como consultores. O estudo mostra que os alunos procuram os cursos, principalmente, para conseguirem reciclagem profissional e ascensão na carreira, embora exista um número expressivo que busca construir uma nova carreira ou uma carreira paralela como professores.

É importante ressaltar que o estudo apresentado pelos autores citados reflete os ambientes socioeconômicos circundantes, que diferem muito entre as regiões brasileiras, ponto balizador para direcionar o conteúdo dos programas e suas orientações para pequenas e médias empresas ou para organizações sem fins lucrativos. É fator de crítica a não disponibilidade dos estudantes para a dedicação exclusiva aos cursos, o que, provavelmente, reduz o foco nos estudos, mas, 
por outro lado, favorece a interação entre a teoria e a prática da gestão, abrindo novas oportunidades para reflexão.

\subsection{O programa de mestrado profissional analisado neste estudo}

\subsubsection{Principais características do programa}

O curso passou a ser oferecido em 2003, e obteve sua recomendação junto ao MEC e a CAPES no ano de 2004. As diretrizes do curso seguem as referendadas pela CAPES para os mestrados profissionais e também as linhas mestras da pós-graduação da universidade em que se insere. Foi criado para oferecer uma contribuição efetiva à melhoria da competitividade das empresas da região e como resposta aos seus desafios de crescimento e desenvolvimento. Está voltado ao enfoque científico para a solução de problemas de gestão nas organizações, favorecendo a reflexão de práticas profissionais. Podem ingressar no curso até 25 alunos por ano.

Os objetivos do MPA são os seguintes:

- proporcionar enfoque científico para solução de problemas de gestão nas organizações, formando dirigentes com visão crítica;

- oferecer aporte de conteúdos teóricos que favoreçam a reflexão e a compreensão de práticas profissionais;

- promover integração entre a universidade e empresas da região, favorecendo análises contextualizadas das dificuldades de gestão.

\subsubsection{Missão}

A missão do curso é formar profissionais qualificados, conferindo-lhes o grau de mestre, para atender à demanda socioeconômica da região, posicionando-se como importante elo entre a cadeia produtiva e os avanços científico-tecnológicos da região.

\subsubsection{Público-alvo}

Destina-se a egressos de cursos superiores em Administração e áreas correlatas, interessados no aprofundamento do conhecimento e desenvolvimento de competências, e que tenham atividades profissionais vinculadas a organizações públicas ou privadas.

\subsection{4 Áreas de concentração}

O MPA tem como área de concentração o estudo em Gestão de Organizações e Negócios, com duas linhas de pesquisa: Marketing e Estratégia e Estudos Organizacionais e de Negócios.

\subsubsection{Estrutura do curso}

Os alunos devem cursar ao menos cinco disciplinas, demonstrar desempenho satisfatório em um conjunto de atividades supervisionadas pelo professor orientador e, ao final do curso, defender e ter aprovada, perante banca examinadora, a dissertação. 


\section{Metodologia}

Na primeira semana de março de 2007, foram enviados e-mails a todos os 78 ex-alunos do curso que já haviam obtido o título de mestre, solicitando que preenchessem questionário eletrônico de pesquisa e o retornassem, por e-mail, aos autores do estudo. Passados quatro dias de envio do e-mail, apenas $22(28,2 \%)$ questionários haviam retornado preenchidos; foi enviado, então, e-mail de reforço aos ex-alunos que ainda não haviam respondido. Dois dias depois, outros sete $(9,0 \%)$ questionários retornaram preenchidos. Novo e-mail foi enviado, e, após três dias, outros três questionários retornaram corretamente preenchidos. O tamanho final da amostra deste estudo é, portanto, de 32 respondentes, o que corresponde a um índice de resposta de $41,0 \%$.

O questionário enviado aos ex-alunos e utilizado nesta pesquisa pode ser visualizado no Apêndice A.

\section{Análises e Resultados}

A amostra do estudo contou com 32 ex-alunos do curso de mestrado profissional, formados nos anos de 2004, 2005 e 2006.

Dos 32 ex-alunos, 27 (84,4\%) são do sexo masculino, enquanto cinco (15,6\%), do sexo feminino. A idade dos respondentes variou entre 24 e 52 anos, sendo a média 38,5. Conforme se pode constatar pela observação do gráfico 1 , há grande dispersão na idade dos alunos que frequentaram o curso.

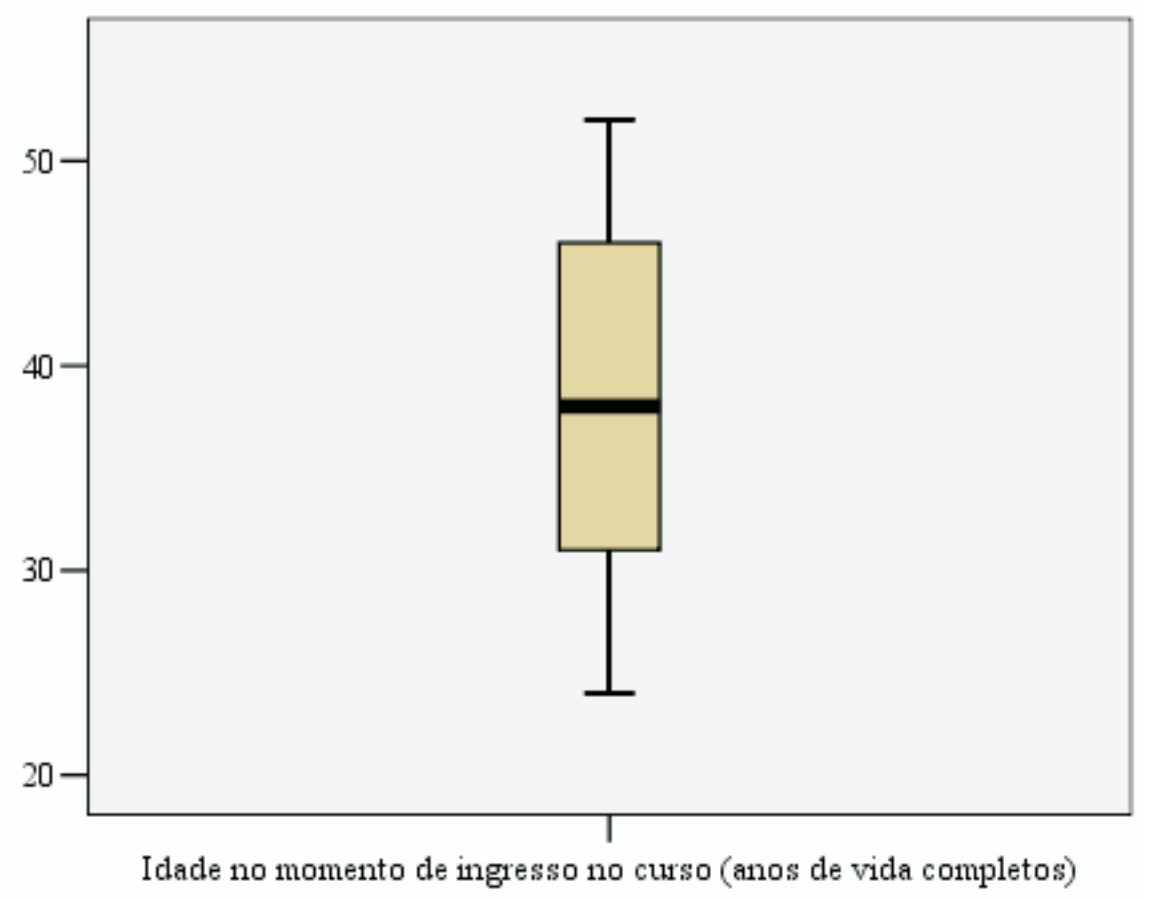

Gráfico 1 - Boxplot para a Variável Idade

Fonte: elaborado pelos autores com auxílio do pacote estatístico SPSS 13.0. 
Dos 32 ex-alunos, nove $(28,1 \%)$ já eram professores antes de ingressar no mestrado profissional; os demais 23 exerciam atividades profissionais no mercado, em cargos tais como: diretoria (três alunos), gerência (quatro alunos), coordenadoria (oito alunos), consultoria (quatro alunos), técnicos (dois alunos) e outros (dois alunos).

No momento de ingresso no curso, a grande maioria dos alunos estava empregada em empresas privadas (29 alunos ou 90,3\% do total), e o restante em empresa pública (um aluno) e no terceiro setor (dois alunos). Quando perguntados a respeito de como pagaram as mensalidades do curso, 23 alunos $(71,9 \%)$ responderam que pagaram por conta própria, enquanto cinco $(15,6 \%)$ tiveram bolsas parciais das empresas em que trabalhavam, três $(9,4 \%)$ tiveram bolsas parciais das instituições de ensino em que trabalhavam e um $(3,1 \%)$ teve bolsa integral da instituição de ensino em que trabalhava. O tempo médio de experiência profissional, no momento de ingresso, foi de 17,5 anos, sendo o desvio-padrão para essa medida, 9,88 anos. O gráfico 2, a seguir, exibe informações relativas à experiência profissional dos alunos.

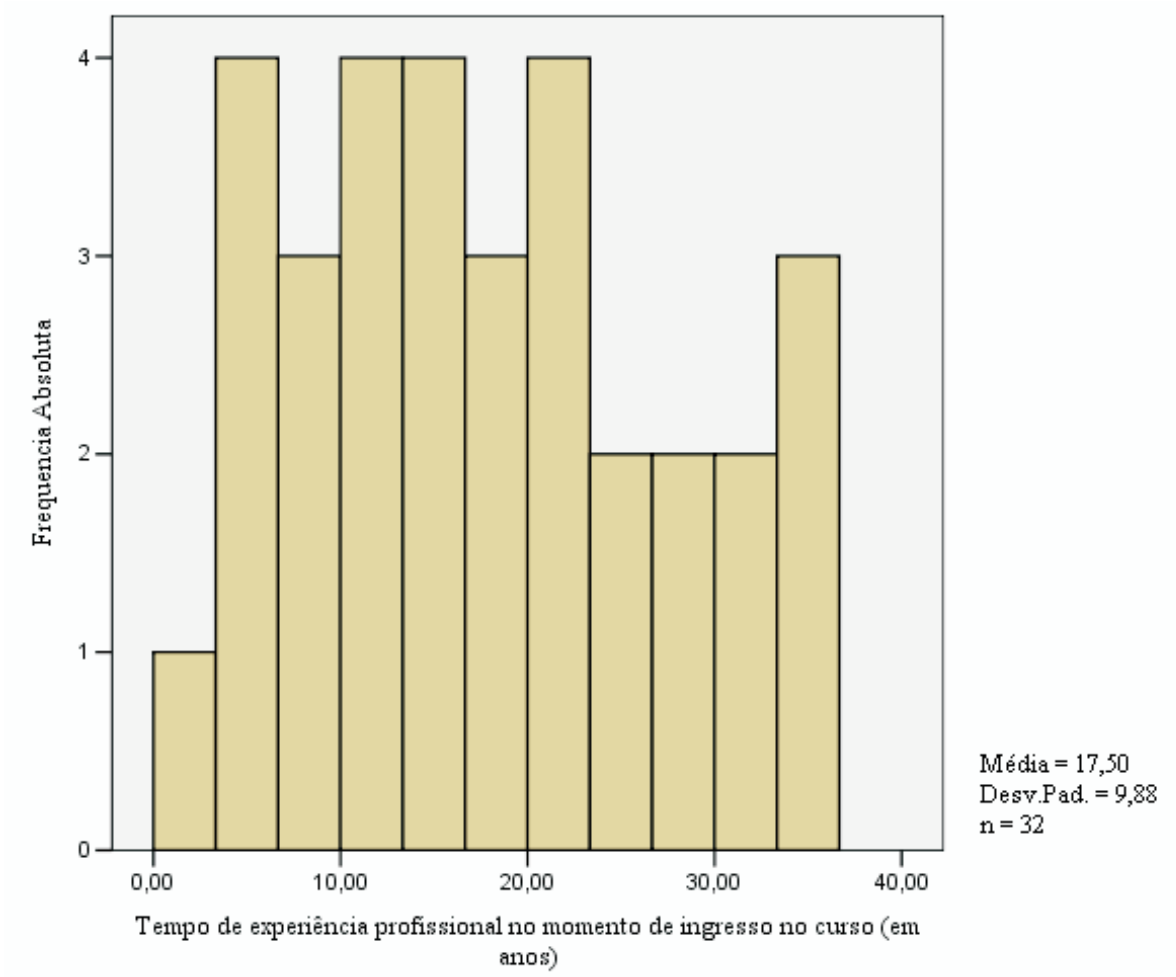

Gráfico 2 - Histograma do tempo de experiência profissional no momento de ingresso no curso

Fonte: elaborado pelos autores com auxílio do pacote estatístico SPSS 13.0.

Os respondentes foram solicitados a classificar quatro sentenças a respeito dos motivos que os levaram a se matricularem no curso de mestrado profissional, segundo sua ordem de importância; a tabela 1 resume os resultados encontrados.

A frase citada com maior frequência, dentre as listadas na tabela 1, foi a 'd': "Formação mais qualificada para atuar com a docência e pesquisa".

Embora o tamanho da amostra seja pequeno e restrinja o poder de generalização das conclusões deste estudo, pode-se afirmar que não há evidência para validar a proposição de pesquisa, segundo a qual "a maioria dos alunos do mestrado considera as atividades acadêmicas de magistério e pesquisa como complementares, preferindo como ocupação principal a qualificação de alto nível para atuar no mercado empresarial". 
Tabela 1 - Atribuição de importância a quatro sentenças a respeito de motivos que levaram os alunos a matricularem-se no curso

\begin{tabular}{l|c|c|c|c|c}
\hline Sentença & $\mathbf{1}\left({ }^{*}\right)$ & $\mathbf{2}$ & $\mathbf{3}$ & $\mathbf{4}$ & $\begin{array}{c}\text { Missing } \\
\text { Values }\end{array}$ \\
\hline $\begin{array}{l}\text { (a) Formação mais qualificada para continuar } \\
\text { atuando no setor empresarial somente }\end{array}$ & 3 & 3 & 5 & 11 & 10 \\
\hline $\begin{array}{l}\text { (b) Formação mais qualificada para } \\
\text { transferência de conhecimento científico para } \\
\text { as empresas ou para o mercado }\end{array}$ & 3 & 9 & 10 & 1 & 9 \\
\hline $\begin{array}{l}\text { (c) Formação mais qualificada para continuar } \\
\text { atuando no setor empresarial como atividade } \\
\text { principal e buscar, em médio prazo, exercer a } \\
\text { docência }\end{array}$ & 10 & 8 & 4 & 5 & 5 \\
\hline $\begin{array}{l}\text { (d) Formação mais qualificada para atuar com a } \\
\text { docência e pesquisa }\end{array}$ & 16 & 3 & 4 & 4 & 5 \\
\hline
\end{tabular}

Nota: $\left(^{*}\right) 1=$ mais importante; 4 = menos importante. Cada respondente deveria atribuir números de 1 a 4 para cada uma das frases, sem repetição.

Fonte: elaborado pelos autores.

Embora poucos alunos procurem o mestrado profissional com interesse exclusivo em melhorar sua qualificação para atuar no setor empresarial, 30 alunos (93,4\%) acreditam que o curso tenha sido útil para suas atividades profissionais. Um dado interessante, em linha com os apresentados na tabela 1, aponta que $28(87,5 \%)$ alunos pretendem continuar seus estudos de pós-graduação em nível de doutorado.

Quando perguntados sobre seus interesses em ministrar aulas, todos os 32 alunos apresentaram respostas positivas, sendo o maior interesse por cursos de especialização (26 alunos, ou $81,3 \%$ ), seguidos por cursos de graduação (23 alunos ou 71,9\%).

Os alunos responderam também seis questões relativas às dissertações que defenderam. Utilizou-se escala Likert de 5 pontos para aferir as respostas, sintetizadas na tabela 2.

Tabela 2 - Estatísticas descritivas das perguntas medidas em escala likert de 5 pontos

\begin{tabular}{clccccc}
\hline Item & Descrição & $\mathbf{n}$ & Mín. & Máx. & Média & $\begin{array}{c}\text { Desvio- } \\
\text { padrão }\end{array}$ \\
\hline 1 & $\begin{array}{l}\text { O tema desenvolvido relacionou-se } \\
\text { com minha atividade profissional }\end{array}$ & 32 & 1 & 5 & 4,66 & 0,87 \\
\hline 2 & $\begin{array}{l}\text { Minha experiência profissional } \\
\text { contribuiu para o desenvolvimento } \\
\text { da dissertação }\end{array}$ & 32 & 3 & 5 & 4,63 & 0,71 \\
\hline 3 & $\begin{array}{l}\text { O tema desenvolvido não possui } \\
\text { cunho exclusivamente acadêmico }\end{array}$ & 32 & 1 & 5 & 4,03 & 1,68 \\
\hline 4 & $\begin{array}{l}\text { O tema desenvolvido permitiu } \\
\text { capacitar-me na análise de meu } \\
\text { cotidiano de trabalho em bases } \\
\text { científicas }\end{array}$ & 32 & 1 & 5 & 4,47 & 0,98 \\
\hline 5 & $\begin{array}{l}\text { A organização em que atuo } \\
\text { beneficiou-se dos conhecimentos } \\
\text { que adquiri no curso }\end{array}$ & 32 & 1 & 5 & 3,78 & 1,45 \\
\hline $\begin{array}{l}\text { Otema desenvolvido não se } \\
\text { relacionou com minha atividade } \\
\text { profissional }\end{array}$ & 32 & 1 & 5 & 1,56 & 1,24 \\
\hline
\end{tabular}

Fonte: elaborado pelos autores. 
Os mais altos graus de concordância são expressos para os itens que dizem respeito ao relacionamento dos temas tratados nas dissertações com as atividades profissionais dos alunos e à contribuição da experiência profissional ao desenvolvimento dos temas abordados nas dissertações. O item ' 6 ' é medido em escala invertida se comparado ao item '1'; este artifício, de acordo com Nunnally (1978) e Churchill (1979), é útil para testar a confiabilidade da escala e a atenção dos respondentes ao expressarem suas respostas. A simetria encontrada entre as respostas desses dois itens é um indicador de qualidade dos dados utilizados nas análises.

Entre os seis itens mensurados, o que capturou menor grau de concordância entre os respondentes foi o de número ' 5 ': "A organização em que atuo beneficiou-se dos conhecimentos que adquiri no curso". Esse aspecto é preocupante no sentido em que não corrobora uma das prerrogativas do curso, que é a transferência de conhecimentos da universidade para as empresas.

\section{Considerações Finais}

Este estudo, realizado com 32 ex-alunos que correspondem a 41,0\% do universo de titulados em um programa de mestrado profissional em Administração reconhecido pelo MEC e pela CAPES em 2004, permitiu confrontar o perfil profissiográfico dos egressos às expectativas da coordenação do curso e às da própria CAPES.

Constata-se que o programa é bem-sucedido em selecionar profissionais com variada experiência profissional; no entanto, supondo-se que as conclusões do estudo de Wood Jr. e Paula (2004) sejam extensíveis a este contexto, ou seja, que os alunos procuraram o curso principalmente para conseguirem reciclagem profissional e ascensão na carreira, pode-se concluir que, em algum momento ao longo do curso, esses alunos mudaram de opinião: um número de $28(87,5 \%)$ alunos pretende continuar seus estudos em nível de doutorado, e a totalidade dos respondentes expressou desejo em ministrar aulas.

Vale ressaltar, no entanto, que metade dos respondentes (16) destacou o programa como uma grande oportunidade para buscarem maior qualificação profissional e continuarem atuando no meio empresarial, muito embora com planos para exercer a docência em curto ou médio prazo.

\section{Limitações e sugestões para estudos futuros}

Este estudo limita-se a analisar dados de egressos do programa de mestrado profissional; idealmente, poder-se-ia somar aos dados disponíveis informações a respeito da expectativa dos alunos para com o curso no momento de seu ingresso.

O número de 32 respondentes é relativamente pequeno para se efetuar quaisquer generalizações, motivo pelo qual se recomendam replicações deste estudo em outros programas e em outros contextos.

Por fim, não se elaborou análises de viés de resposta: é possível que os 46 ex-alunos que não responderam ao questionário apresentassem padrões de comportamento diferentes dos que responderam. 


\section{Referências Bibliográficas}

ANTONACOPOULOU, E. P. Teaching "critical thinking" to MBAs. In: INTERNATIONAL CRITICAL MANAGEMENT STUDIES CONFERENCE, 1., 1999, Manchester. Proceedings... Manchester: UMIST, 1999.

BARROS, E. C. de; VALENTIM, M. C.; MELO, M. A. A. O debate sobre o mestrado profissional na Capes: trajetória e definições. BBPG, v. 2, n. 4, p. 123-138, jul. 2005.

BOJE, D. M. Management education as a panoptic age. In: FRENCH, R; GREY, C. (Eds.). Rethinking management education. London: Sage, 1996. p. 172-195.

CAPES. Coordenação do Pessoal de Ensino Superior. Portaria n. 80, de 16/12/1998. Reconhecimento dos Mestrados Profissionais - Diário Oficial, 11/01/ 1999 seção 1, p. 14.

Disponível em: <http:// www.capes.gov.br>. Acesso em: 22 set. 2006.

CASTRO, C. de M. A hora do mestrado profissional. Revista RBPG, Brasília, v. 2, n.4, p. 16-23, jul. 2005.

CHURCHILL, G. A. Paradigm for developing better measures of marketing constructs. Journal of Marketing Research, Chicago, v. 16, n. 1, p. 64-73, Feb. 1979.

CUNHA, Luiz Antonio C. R. A pós-graduação no Brasil: função técnica e função social. Revista de Administração de Empresas, Rio de Janeiro, v. 14, n. 5, p. 66-70, set./out. 1974a.

CUNHA, L. A. C. R. Trecho da exposição de motivos do Ministério da Educação e Cultura que acompanhou o projeto de criação do Conselho Nacional de Pós-Graduação. Jornal do Brasil, 19 o cad., p. 7, 05/04/1974b.

DEHLER, G; WELSH, M. A.; LEWIS, M. W. Critical pedagogy in the "new paradigm": raising complicated understanding in management learning. In: INTERNATIONAL CRITICAL MANAGEMENT STUDIES CONFERENCE, 1., 1999, Manchester. Proceedings... Manchester: UMIST, 1999.

FISCHER, Tânia. Pós-graduação e mestrado profissional: o que há de novo? In: ASSEMBLÉIA DO CON-
SELHO LATINO-AMERICANO DE ESCOLAS DE ADMINISTRAÇÃO, 37., 2002, Porto Alegre. Anais... Porto Alegre: CLADEA, 2002.

Seduções e riscos: a experiência do mestrado profissional. Revista de Administração de Empresas, Rio de Janeiro, p. 119-123, abr.jun. 2003.

. Programa de Capacitação Docente em Administração - PCDA. E \& G Economia e Gestão, Belo Horizonte, v. 5, n. 11, p. 193-194, dez. 2005.

FOX, S.; GREY, C. Introduction connecting learning and critique. Management Learning, v. 31, n. 1, p. 7-10, 2000.

GIOIA, D. A.; CORLEY, K. G. Being good versus looking good: business scholl rankings and the circean transformation from substance to image. Academy of Management Learning and Education, v. 1, n. 1, p. 107-120, 2002.

GOLD, J.; HOLMAN, D.; THORPE, R. The manager as a critical reflective practitioner: uncovering arguments at work. In: INTERNATIONAL CRITICAL MANAGEMENT STUDIES CONFERENCE, 1., 1999, Manchester. Proceedings... Manchester: UMIST, 1999.

GOUVÊA, M. A.; ZWICKER, R. O mestrado profissionalizante e o perfil dos alunos de um mestrado acadêmico: resultados de uma pesquisa empírica. Caderno de Pesquisas em Administração, São Paulo, v. 7, n. 3, p. 99-110, jul./set. 2000.

GREY, C.; KNIGHTS, D.; WILLMOTT, H. Is a critical pedagogy of management possible? In: FRENCH, R.; GREY, C. (Eds.). Rethinking management education. London: Sage, 1996. p. 94-110.

IKEDA, A.; CAMPOMAR, M. C.; OLIVEIRA, T. M. V. A pós-graduação em Administração no Brasil definições e esclarecimentos. Revista Gestão e Planejamento, Salvador, ano. 6, n. 12, p. 33-41, jul./dez. 2005.

LHULLIER, L. A. Os objetivos do CPGA/UFRGS e a situação de seus egressos no mercado de trabalho. Dissertação (Mestrado em Administração)-Faculdade de Administração, Universidade Federal do Rio Grande do Sul, Porto Alegre, 1978. 
MATTOS, P. L. Dissertações não acadêmicas e mestrados profissionais: isso é possível? Revista de Administração Contemporânea, Curitiba, v. 1, n. 2, p. 153-173, maio/ago. 1997.

MINTZBERG, H.; GOSLING, J. Educating managers beyong borders. Academy of Management and Education, v. 1, n 1, 2002. p. 64-76.

MINTZBERG, H.; LAMPEL, J. MBAs as CEOs. Fortune. Feb. 2001. Disponível em: http:// courseware.finntrack.eu/mba/mb111/ mbasasceos.pdf. Acesso em: 20 abr. 2005.

MOTTA, E. de O. Direito educacional e educação no século XXI: com comentários à nova Lei de Diretrizes e Bases da Educação Nacional. Brasília: UNESCO, 1997.

NUNNALLY, J. C. Psychometric theory. New York: McGraw-Hill, 1978. 701 p.

PARECER CNE/CES 0079/2002. Disponível em: $<$ http://portal.mec.gov.br/cne/arquivos/pdf/2002/

pces079_02.pdf>. Acesso em: 20 abr. 2005.

PIQUET, R.; LEAL, J. A. A. O mestrado profissional: proposta polêmica no sistema brasileiro de pós-graduação - o caso do planejamento regional e urbano. RBPG, Brasília, v. 2, n. 4, p. 30-37, jul. 2005.

QUELHAS, O. L. G.; FARIA, J. R. F.; FRANÇA, S. L. B.. O mestrado profissional no contexto do sistema de pós-graduação brasileiro. RBPG, Brasília, v. 2, n. 14, p. 97-104, jul. 2005.
RIBEIRO, R. J. O mestrado profissional na política atual da Capes. RBPG, Brasília, v. 2, n. 4, p. 8-15, jul. 2005.

RUAS, R. Mestrado modalidade profissional: em busca da identidade. Fórum Educação em Administração. Revista de Administração de Empresas, Rio de Janeiro, v. 43, n. 2, p. 55-63, abr./maio/jun. 2003.

SPSS 13.0 for Windows, version 13.0: statistical software. [S.I.]: SPSS Inc., 2004.

VELOSO, J. et al. Mestres e doutores no Brasil: destinos profissionais e modelos de pós-graduação. Plano Nacional de Pós-Graduação 2005-2010. Disponível em: <http://www.capes.gov.br/capes/portal/ conteudo/PNPG_2005_2010.doc >. Acesso em: 20 abr. 2005.

WARDE, I. Fascinantes business schools. Le Monde Diplomatique, v. 1, n 3, maio 2000. Disponível em: <http://www.diplo.com.br>. Acesso em: 20 jan. 06.

WARNER, A. Where business schools fail to meet business needs. Personnel Management, v. 22, n. 7, p. 46-52, 1990.

WILLMOTT, H. Management education: provocations to a debate. Management Learning, v. 25, n. 1, p. 135-152, 1994.

WOOD, T. Jr.; PAULA, A. P. P. O fenômeno dos MPAs Brasileiros: hibridismo, diversidade e tensões. Revista de Administração de Empresas, Rio de Janeiro, v. 44, n. 1, p. 116-128, 1990.

\section{Apêndice A: Questionário Enviado aos Participantes do Estudo}

1a. Gênero [masculino] [feminino]

1b. Qual sua idade no momento de ingresso no curso?

2. Qual atividade profissional você exercia no momento de ingresso no curso?

[diretor] [gerente] [coordenador] [analista] [consultor] [técnico] [professor] [funcionário público] [assessor] [outro:

3. Qual o tipo de empregador (relacionado à atividade profissional informada no item anterior)? [Empresa privada] [Empresa Pública] [Terceiro Setor] 
4. Informe o tempo de experiência profissional no momento de ingresso no curso (em anos e meses).

5. Qual o motivo que o levou a procurar o curso de pós-graduação stricto sensu Mestrado Profissional? (Classificar os itens em ordem de importância de 1 a 4, sendo 1 o mais importante e 4 o menos importante)

[5.1. Formação mais qualificada para continuar atuando no setor empresarial somente]

[5.2. Formação mais qualificada para transferência de conhecimento científico para as empresas ou para o mercado]

[5.3. Formação mais qualificada para continuar atuando no setor empresarial como atividade principal e buscar em médio prazo exercer a docência]

[5.4. Formação mais qualificada para atuar com a docência e pesquisa]

6. O investimento financeiro referente à mensalidade do curso foi subsidiado

[por conta própria] [bolsa parcial da empresa: \%] [bolsa integral da empresa] [bolsa parcial de instituição educacional: \%] [bolsa integral de instituição educacional]

7. O curso foi útil para as suas atividades profissionais? [sim] [não] Justificativa.

8. Você tem interesse em ministrar aulas em cursos de: [graduação] [especialização] [outros]

9. Você tem interesse em continuar seus estudos de pós-graduação em nível de Doutorado? [sim] [não] Justificativa.

10. Quanto à sua dissertação defendida, atribuir notas de (1) discordo totalmente a (5) concordo totalmente:

[10.1. O tema desenvolvido relacionou-se com minha atividade profissional]

[10.2. Minha experiência profissional contribuiu para o desenvolvimento da dissertação]

[10.3. O tema desenvolvido não possui cunho exclusivamente acadêmico]

[10.4. O tema desenvolvido permitiu capacitar-me na análise de meu cotidiano de trabalho em bases científicas] curso]

[10.5. A organização em que atuo beneficiou-se dos conhecimentos que adquiri no

[10.6. O tema desenvolvido não se relacionou com minha atividade profissional] 